Available online at www.refaad.com

VMPH, 1(1)2020, 3-4

Case Report

Veterinary Medicine and Public Health Journal (VMPH)

Journal Homepage: https://www.refaad.com/views/vmph/home.aspx

\title{
Postmortem evidence of abomasal coccidiosis in awassi lamb in Jordan
}

\author{
Wael Hananeh DVM, MSc, Dipl. ACVP ${ }^{a *}$ \\ ${ }^{a}$ Department of Veterinary Pathology and Public Health, Faculty of Veterinary Medicine. \\ *Corresponding author: Wael Hananeh (whananeh@just.edu.jo)
}

How to cite this article: Hananeh W. Postmortem Evidence of Abomasal Coccidiosis in Awassi lamb in Jordan, Veterinary Medicine and Public Health Journal, 1(1);(2020): 3-4.

DOI:

https://doi.org/10.31559/vmph2020.1.1.2

Received Date: 9/10/2019 Accepted Date: 12/11/2019

\begin{abstract}
Abomasal coccidiosis was incidentally diagnosed in a 2- week-old female Awassi sheep that was found dead. No significant gross lesions were found in the abomasum. Histologically, one or two intact gigantic coccidian schizonts with no or minimal lymphocytic inflammation were demonstrated mainly in the deep abomasal mucosa. No other coccidial stages were detected throughout the examined sections. These histologic features were consistent with Eimeria girluthi. To the best of my knowledge, this is the first case of abomasal coccidiosis in Awassi sheep in Jordan.
\end{abstract}

Keywords: Abomasum; globidium; Eimeria; sheep.

\section{Introduction}

Abomasal coccidiosis caused by Eimeria girluthi (E. girluthi) infection had been often reported as sporadic cases in sheep (Mahmoud 1997; Maratea and Miller 2007) and goats (Maratea and Miller 2007) from different parts of the world. It is believed that E. girluthi infections are generally incidental and characterized by the presence of giant schizonts mainly within the mucosa of the abomasum (Maratea and Miller 2007; Hermosilla 2016). In this article, a case of abomasal coccidiosis in an Awassi sheep is described.

\section{Case report}

A 2-week-old, female Awassi lamb was submitted dead to the Veterinary Health Center, Faculty of Veterinary Medicine at Jordan University of Science and Technology for necropsy examination. The lamb was in a poor body condition. At necropsy, no significant gross lesions were present in any of the organs.

Representative tissue samples from the entire organs were selected and fixed in 10\% neutral buffered formalin for 48 hours. The fixed tissues were routinely processed through an automatic histoprocessor. After that, the tissues were embedded in paraffin, sectioned, and stained with hematoxylin and eosin (HE) stain according to Suvarna et al. (2018).
Histologically, the abomasal mucosa exhibited no significant histopathological abnormalities throughout the examined tissue sections except two large schizonts that were located mainly within the deep mucosa. These schizonts were round to ovoid measuring approximately $300 \mu \mathrm{m}$ in diameter. These schizonts walled off with a very thick homogenous eosinophilic wall, $10-15 \mu \mathrm{m}$ thick. They contained myriads of merozoites. No inflammatory reactions were seen associated with these schizonts however; minimal lymphocytic infiltrates were seen surrounding very few schizonts (Fig.1). No other histopathological findings were significant.

\section{Discussion}

The morphological features of the large intact schizonts within the abomasal mucosa of sheep are consistent with E. girluthi infection. These morphological features of the E. girluthi schizonts were previously reported (Hilali 1973; Hermosilla 2016). Lack of other stages of coccidia throughout the examined tissue sections confirmed the diagnosis of $E$. girluthi infection in this sheep since only the schizont stage of $E$. girluthi is known. Furthermore, in most cases, E. girluthi was diagnosed incidentally since no associated marked inflammation was associated with this type of infection which supports the diagnosis. In a previously conducted study in Najdi sheep that died 
due acute pneumonia, Mahmoud (1997) reported the presence of such parasite in the abomasae of those dead lambs with mild gastric lesions. However, few reports described the pathological lesions of E. girluthi in the abomasm of sheep ( Maratea and Miller 2007; Hermosilla 2016; Ammar et al. 2019). E. girluthi infection was reported in a group of ewe suffering from weight loss and diarrhea (Ammar et al. 2019). In those ewes, pinpoint white nodules were seen in the abomasal mucosae corresponded to the histologic features of the large schizonts of E. girluthi (Ammar et al. 2019). In another study, 3\% of the examined sheep had gross lesions of abomasal coccidiosis and one of them showed severe granulomatous abomasitis associated with degenerate schizont (KhodakaramTafti et al. 2015). Moreover, proliferative abomasitis was associated with abomasal coccidiosis, and hence it should be included as a differential disease to teladorsagiosis.

To the best of the author's knowledge, this is the first report of incidental abomasal coccidiosis in Awassi sheep in Jordan with no associated prominent clinical, gross and or histopathological lesions.

\section{Conflicts of interests}

The author declares that he has no competing interests.

\section{Acknowledgements}

The author would like to acknowledge the Pathology laboratory personnel for their slides.
Note

Refaad and VMPHJ remain neutral with regard to jurisdictional claims in published institutional affiliation.

\section{References}

[1] Ammar. SI, Watson. AM, Craig. LE, Cope. ER, Schaefer. JJ, Mulliniks. JT \& Gerhold. RW, Eimeria gilruthi-associated abomasitis in a group of ewes, J Vet Diagn Invest, 31(1)(2019), 128-132, https://doi.org/10.1177/1040638718814109

[2] Hermosilla .C. , Fatal Eimeria gilruthi-induced abomasal coccidiosis: a still neglected parasitosis?, J Vet Med Res, 3(4)(2016), 1055.

[3] Hilali. M, Studies on globidial schizonts in the abomasum of Norwegian sheep. The fine structure of one of the four merozoite forms investigated, Acta Vet Scand, 14(1)(1973), 22.

[4] Khodakaram-Tafti. A., Hajimohammadi. A. \& Amiri. F., Prevalence and pathology of abomasal abnormalities in sheep in southern Iran, Bulg J Vet Med, 18(3)(2015), 270-276, https://doi.org/10.15547/bjvm.802

[5] Mahmoud. O., Eimeria gilruthi infection in Nadji lambs in Gassim region of central Saudi Arabia, Trop Anim Health Prod , 29(4)(1997), 249-250, https://doi.org/10.1007/bf02632316

[6] Maratea. KA. \& Miller. MA., Abomasal coccidiosis associated with proliferative abomasitis in a sheep, J Vet Diagn Invest, 19(1)(2007), 118-121, https://doi.org/10.1177/104063870701900122

[7] Suvarna. KS., Layton. C. \& Bancroft. JD., Bancroft's Theory and Practice of Histological Techniques EBook, Elsevier Health Sciences, (2018

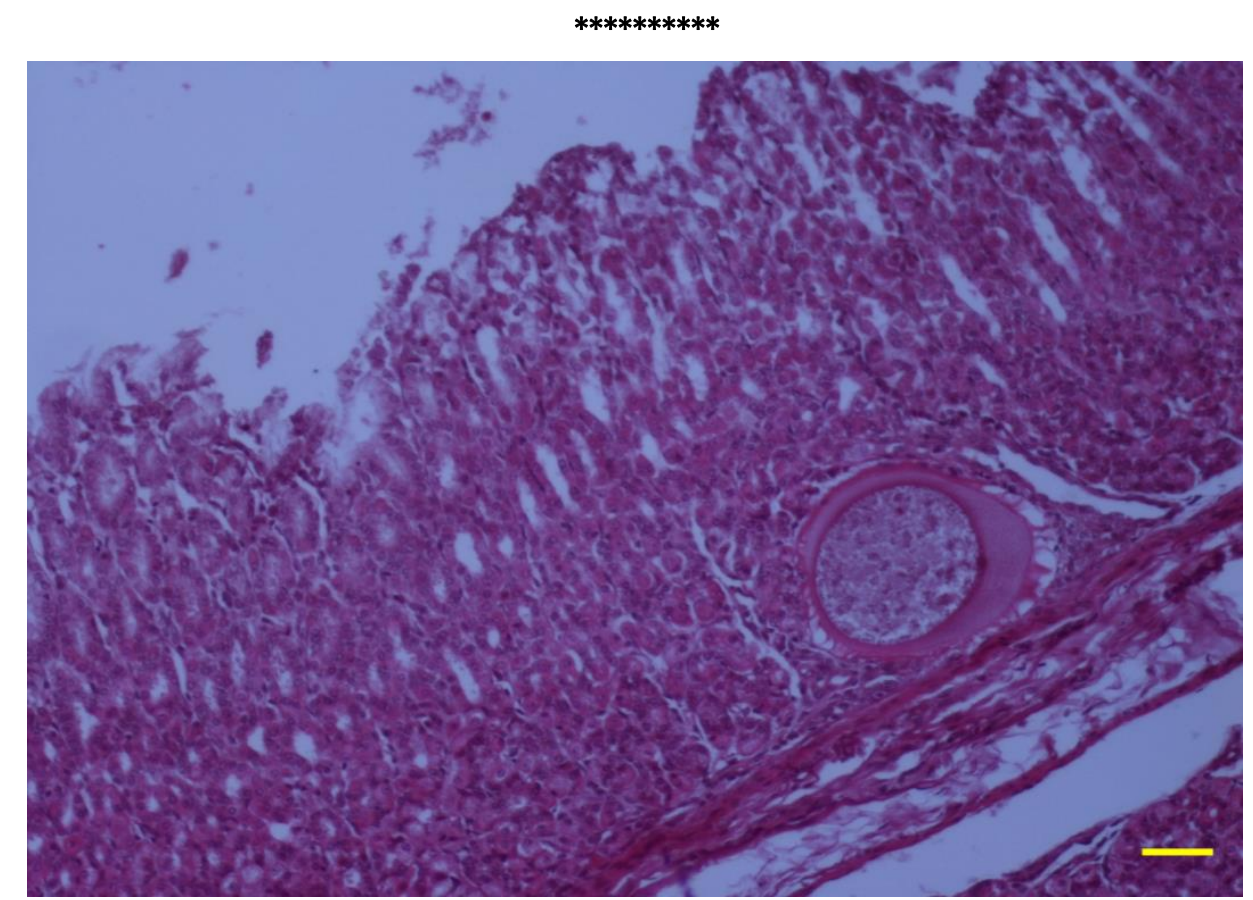

Fig (1): A large Eimeria spp. schizont in the deep abomasal mucosa is surrounded by minimal lymphocytic infiltrates. The schizont exhibits a thick homogenous eosinophilic wall containing myriads of merozoites. H\&E stain. Bar $=100 \mu \mathrm{m}$. 